\title{
The Current Situation, Problems and Improvement of Ex-ante Performance Management in China
}

\author{
Qin-yun He ${ }^{1}$, Yan Li ${ }^{1}$, Chuan Tian ${ }^{2}$ \\ ${ }^{1}$ School of Public Finance and Tax, Central University of Finance and Economics, Beijing, P. R. China \\ ${ }^{2}$ Bank of Weifang, Weifang, P. R. China
}

\section{Email address:}

mia_ho153@163.com (Qin-yun He),m15388331539@163.com (Yan Li),m15605360312@163.com (Chuan Tian)

\section{To cite this article:}

Qin-yun He, Yan Li, Chuan Tian. The Current Situation, Problems and Improvement of Ex-ante Performance Management in China. Science Journal of Business and Management. Vol. 8, No. 1, 2020, pp. 16-26. doi: 10.11648/j.sjbm.20200801.13

Received: December 3, 2019; Accepted: January 14, 2020; Published: February 3, 2020

\begin{abstract}
Budget decision-making is the first step in the process of budget management, which can have a huge impact on the effect of budget management. The correct decision can make budget expenditure achieve expected output, and the wrong decision will lead to a serious waste of budget funds. Therefore, improving the level of budget decision is the key to the full implementation of budget performance management in China. Ex-ante performance management is located in the front of budget management. It is to collect, sort out and analyze relevant information purposefully and systematically before budget decision-making. So, ex-ante performance management can provide scientific basis for budget decision-making and effectively improve the level of budget decision-making, which is of great significance to ensure the implementation effect of comprehensive budget performance management in China. Therefore, it is necessary to study the current situation of China's performance management in advance, find out the problems existing in the performance management in advance and put forward the corresponding countermeasures. This paper first clarifies the background of the implementation of Ex-ante performance management, then studies the current situation and existing problems of the implementation of Ex-ante performance management from the central and local perspectives, and finally puts forward corresponding countermeasures and suggestions.
\end{abstract}

Keywords: Budget, Ex-ante Management, Budget Decision

\section{Introduction}

The report of the 19th National Congress of the Communist Party of China put forward that "we should speed up the establishment of a modern financial system and establish a central and local financial relationship with clear powers and responsibilities, financial coordination and regional balance". We will establish a comprehensive, standardized and scientific budget system with strong constraints, and fully implement performance management. We need to deepen the reform of the tax system and improve the local tax system. Subsequently, the Opinions on Implementing Budget Performance Management in an All-round Way (hereinafter referred to as the Opinions) issued by the CPC Central Committee and the State Council pointed out that "implementing budget performance management in an all-round way is the internal requirement for promoting the modernization of national governance system and governance capacity". Budget performance management is a result oriented budget management mode. To some extent, it alleviates the shortcomings of the "investment control orientation" budget mode, realizes the effective management of the use of government funds, and improves the efficiency of the use of financial funds. As the front-end of budget management, budget decision-making determines the allocation of budget funds, affects public budget activities and results, so to improve the efficiency of allocation and use of financial resources, the key is to improve the scientific nature of public budget decision-making.

The reform of performance budget management in China started from the "establishment of budget performance evaluation system" proposed at the Third Plenary Session of the 16th CPC Central Committee, hoping to improve the performance of the use of financial funds through post evaluation, but in practice, post performance evaluation has a very limited role in improving the efficiency of the use of financial funds. The main reason is that the results of performance evaluation after the event have not been 
effectively used, and the separation of performance and budget cannot make the budget unit change the awareness of "putting more emphasis on investment than management" and "putting more emphasis on expenditure than performance".

In order to achieve better results in budget performance reform, it is necessary to intervene before expenditure. Building a complete closed-loop budget performance management system with ex-ante prevention, in-process supervision and ex post pursuit. Ex-ante performance management is the first step of the whole process management, and it is a good foundation to guarantee the development of budget performance management in and after the event. Therefore, to solve the separation of performance and budget problem and integrate performance management into budget management, the first thing is to make performance information really be used in budget decision-making and improve the scientificity of budget decision-making.

Ex-ante performance management in China is based on the summary of post performance evaluation experience. It is a new model of budget performance management based on project library management and supported by performance objectives and ex-ante evaluation. In advance performance management, the key of budget performance management is moved forward to the front of budget decision-making, so as to avoid decision-making mistakes as much as possible and ensure that the "first button" of budget management is properly buttoned. In 2014, the newly revised Budget Law of the People's Republic of China determined "performance objective management" in the form of law for the first time, and determined the leading position of performance objective management in the whole process management. In 2015, the budget department of the Ministry of Finance issued the Measures for Budget Performance Management of Central Departments (CJ [2015] No. 88), which requires central departments to declare performance objectives when applying for budget, and makes detailed provisions on the setting, review, approval, adjustment and application of performance objectives, standardizes the budget performance objective management of central departments, and the financial department will further improve the performance objectives Line approval is the premise and main basis of budget arrangement.

The integrated management mode of performance goal setting, performance goal auditing and performance evaluation is basically formed in China. In 2018, based on the experience of the budget project ex-ante evaluation implemented in Beijing since 2010, the Opinion proposed to carry out the ex-ante performance evaluation on the newly issued major policies and projects, and broadened the scope of the ex-ante performance evaluation. ex-ante performance management mainly provides more scientific decision-making basis for budget decision-making through performance objective management and performance evaluation in advance, injects "rational" factors into the political nature of budget decision-making, optimizes the allocation of financial resources, and improves the efficiency of the use of financial funds.

\section{Literature Review}

Chinese scholars' research on ex-ante performance management is rich with the promotion of budget performance reform. Budget performance management is the result of performance budgeting in China. It is a new mode of budget management which is the combination of western performance budgeting mode and the reality of budget management in China. Wang Haitao [1] believed that China's budget performance management should not only draw on the concept of foreign performance budget focusing on performance, but also integrate with the reality of China's budget management, and cannot relax compliance management.

Performance target management is the premise and basis of budget performance management, not only an important reference for budget implementation in the event, but also an important basis for post-performance evaluation. Therefore, to ensure the quality of performance target is an important content of ex-ante performance management. Chen Kai [2] believes that the core role of performance objective management must be based on the scientific setting of performance objectives. The setting of performance objectives can not only strengthen the sense of responsibility of fund users, but also improve the use efficiency of financial funds by clarifying the use effect of financial funds in advance, decentralizing the budget implementation unit. Compared with developed countries, China's budget performance management started late, although it has achieved some results, but there are still many problems. Cao Zheng [3] thinks that from the experience of budget performance objective management in China, first of all, there is a lack of talents in budget performance management, which has become the "bottleneck" restricting the development of budget performance objective management in China; Secondly, the financial department lacks the substantive review of performance objectives, which is basically a formal review mode, resulting in the quality of setting performance objectives cannot be effectively improved for a long time, hindering the full implementation of budget performance management in China. Zheng Fengzi [4] analyzed the performance objectives of the financial expenditure projects of the budget department of Shanghai, and found that the performance indicators corresponding to the performance objectives are difficult to measure, the cost of obtaining accurate data is high, the difficulty is great, and the feasibility of implementation is not high, "sound", "effective", "satisfactory" and other words are frequently used, resulting in the subjectivity of performance evaluation, reducing the scientificity of performance objective management. At the same time, the matching degree between performance objectives and budget expenditure is very low, the setting of performance objectives is not combined with the actual situation of the project, and the binding force of performance objectives on the project budget is greatly reduced. In view of the problems existing in performance target management in China, scholars also put forward their own views. According 
to Jiang Shujun [5], it is necessary to strengthen the relationship between performance objectives and strategic objectives, enhance the clarity of setting performance objectives, correctly grasp the difficulty of setting performance objectives and innovate the evaluation mechanism of performance objectives. Tong Wei [6] believes that in view of the existing performance objectives in China, we should start from strengthening the demonstration and verification of performance objectives, strengthening the combination of performance objectives and performance indicator system, strengthening internal and external audit, deepening system construction, optimizing management process and other aspects.

In addition to reviewing the setting of performance objectives, ex-ante performance management should also demonstrate the budget items in advance. In 2010, Beijing innovative proposed ex-ante performance evaluation, which shifted the focus of budget performance management from post to ex-ante. Tong Wei [7] believes that performance evaluation can not only measure whether the performance objectives of government departments are reasonable, but also comprehensively and objectively evaluate the potential risks of the use of financial funds, which is the key to judge whether the government departments are "doing the right thing". He Qing [8] believed that by advancing the time when the NPC and CPPCC influence the budget, the ex-ante assessment can inject more democracy into the budget decision-making, and the multi-agent participation in the performance assessment can more accurately grasp the feasibility, necessity and risk of the financial point out. Zhu Jing [9] interviewed many experts who participated in Beijing's ex-ante performance evaluation, and found that although China's ex-ante performance evaluation is still simple compared with developed countries, the ex-ante performance evaluation has played a significant role in promoting the level of financial budget management. Jiang Zhu [10] thinks that the ex-ante performance evaluation is the key to judge the rationality and effectiveness of financial expenditure, and the key point to control the quality of financial expenditure. She thinks that one of the differences between the ex-ante performance evaluation and the post-performance evaluation is that the former is to consider the effect of financial expenditure from the overall situation, and the latter is to evaluate the effect of financial expenditure from a single project.

Foreign scholars think that the successful symbol of budget performance management is the use of performance information in budget decision-making, but domestic scholars research shows that the problem of public budget decision-making mechanism is large, and performance information has not been effectively used. Nie Fengjie [11] inspected the decision-making mechanism of China's public budget, and found that there are many problems, such as the imperfect legal system, the imperfect allocation of decision-making authority, the low level of decision-making, and the insufficient transparency of decision-making. Ma caichen [12] believes that the public budget decision-making is not timely due to conflicts and frictions in the budget decision-making process, which affects the government's ability of good governance and national governance. Wang Yongjun [13] believes that due to different systems, China's government decision-making is driven from top to bottom. Therefore, compared with western countries, the success of China's decision-making can bring greater success, and the failure of decision-making will inevitably lead to greater failure. The effectiveness of China's decision-making system is closely related to national governance, and budget decision-making is an important part of government decision-making. If the budget decision-making cannot achieve the effective connection between "business" and "money", it is difficult to guarantee the best performance of budget expenditure.

From the above analysis, it can be seen that the domestic scholars' research on the prior performance management and budget decision-making has been very sufficient. They have studied the implementation significance, existing problems and improvement measures of the performance objective management, and demonstrated the importance of the prior performance evaluation from both theoretical and practical aspects. In the aspect of budget decision-making, scholars have demonstrated the problems existing in the budget decision-making system of China, indicated the urgency of improving the budget decision-making mechanism, and formed a large number of research results. Generally speaking, on the one hand, there are few studies that extend the study of performance objectives and performance evaluation to the stage of performance decision-making, so it is difficult to know the direct impact of performance objectives and performance evaluation on performance decision-making. On the other hand, the author thinks that performance objectives and performance evaluation are both components of prior performance management, and it is not conducive to the continuous development of performance budget work of budget units and financial departments to separate the two. Therefore, the author thinks it is necessary to clarify the relationship between performance objective management and performance evaluation, and study the overall impact of the two on the level of performance decision-making.

\section{Implementation Status of Ex-ante Performance Management}

\subsection{The Current Situation of the Central Government's Ex-ante Performance Management}

In 2015, the Ministry of Finance issued the Measures for the management of budget performance objectives of central departments, which implemented the performance objective management for all funds incorporated into the budget management of central departments, and could not arrange the budget for projects without performance objectives or failed to pass the review. It is also required that the performance objectives of all projects should be clearly formulated and reported from the 2016 central department budget, so as to effectively improve the scientificity, standardization and 
effectiveness of performance objective management. In 2018, the Opinion requires to promote budget performance management from "three aspects". The whole process budget performance management first proposes to establish a performance evaluation mechanism, that is, on the basis of the original performance objective management, add a ex-ante event management checkpoint, and improve the budget decision-making level through the dual ex-ante event performance management procedure. The Opinion points out that in addition to the original financial department's review of the new major policies and events budget, if necessary, a third-party organization can be organized to independently carry out performance evaluation, and the opinions of the two can be referred to in the budget arrangement. This shows that China's decision-making mechanism is undergoing major changes, performance budget management will be more involved in budget decision-making, and China's budget decision-making mode is changing from "the will of the chief" and "patting the head" to scientific prediction and democratic decision-making.

In 2016, the Ministry of Finance reviewed all the first level projects reported by one hundred and fifty-three central departments and ninety-three performance targets of special transfer payments from the central government to local governments through centralized joint review. The budget performance management mechanism of "synchronous declaration, synchronous review and synchronous approval" is established to lay a foundation for performance objectives to guide the allocation and use of budget funds. In 2017, the Ministry of Finance submitted sixty-six overall performance targets of special transfer payments from the central government to local governments when submitting the draft budget to the finance and Economic Commission of the National People's Congress; and ten key project performance objectives of ten central departments are selected to be submitted to the Standing Committee of the National People's
Congress for deliberation along with the 2017 department budget draft [14], and then made public for the first time. In 2018 , the central government has expanded the coverage of performance target management from general public budget and government fund budget to some central state-owned capital operation budget projects, and initially established a relatively comprehensive and standardized performance indicator system. The number of key projects submitted to the Standing Committee of the National People's Congress for reference or deliberation increased to thirty-seven, and the number increased to fifty in 2019. The performance objectives of the project are reported to the finance and Economic Committee of the people's Congress and the Standing Committee of the people's Congress along with the budget draft. Through the direct connection between the performance objectives and the budget capital expenditure results, the deputies of the people's Congress can not only understand the government budget arrangement, understand the government work arrangement, but also provide the basis for the people's Congress to judge whether the project should be carried out.

\subsection{The Current Situation of Local Government's Ex-ante Performance Management}

\subsubsection{Ex-ante Performance Evaluation in Beijing}

In 2010, Beijing took the lead in proposing the ex-ante performance evaluation, introducing the ex-ante performance evaluation in the budget preparation and review process, and deciding whether the project will be included in the next year's budget support according to the results of the ex-ante performance evaluation. In 2014, Beijing officially issued the Detailed Rules for the Implementation of the Management of Ex-antePerformance Evaluation of Beijing Municipal Project Expenditure (JCP [2014] No. 1933), marking that Beijing has initially established a ex-ante process system of budget performance management.

Table 1. Results of performance evaluation in advance conducted by Beijing municipal level in 2010-2019.

\begin{tabular}{lllll}
\hline Year & Number of evaluation items & Assess the amount of funds (RMB: million) & Reduction amount (RMB: million) & Reduction rate \\
\hline 2010 & 8 & 1425 & 218 & $15.3 \%$ \\
2011 & 33 & 4867 & 892 & $18.3 \%$ \\
2012 & 36 & 3596 & 631 & $17.5 \%$ \\
2013 & 43 & 3983 & 1030 & $25.9 \%$ \\
2014 & 60 & 4808 & 1283 & $26.7 \%$ \\
$2015^{1}$ & 54 & $5818^{*}$ & - & - \\
$2016^{2}$ & 51 & $6452^{*}$ & $839^{*}$ & $13 \%$ \\
2017 & 70 & 7999 & 1155 & $14.4 \%$ \\
2018 & 42 & 39051 & 322 & $0.82 \%$ \\
2019 & 145 & 8049 & 1492 & $18.54 \%$ \\
\hline
\end{tabular}

Source: 2010-2014 data is from Zhongjing performance management and evaluation network; 2015 and 2016 partial data are from The report on Beijing 2016 budget implementation and 2017 budget and The report on Beijing 2017 budget implementation and 2018 budget; 2017-2019 data is from the website of Beijing Municipal Bureau of finance.

Note: * is the result calculated by the author according to the official data.

\footnotetext{
1 Note: the relevant description in the Report on 2016 budget implementation and 2017 budget of Beijing is: the scale of financial expenditure performance evaluation and prior performance evaluation funds in 2015 increased by $36.4 \%$ and $21.1 \%$ respectively over the ex-antevious year.

2 Note: in the report on the Implementation of Beijing's 2016 budget and 2017 budget, 35 deputies to the National People's Congress were invited to participate in the ex ante performance evaluation of 51 financial project expenditures. The capital scale increased by $10.9 \%$ compared with the ex-antevious year, 22 projects were not supported or partially supported, and the capital reduction rate reached $13 \%$, and the 2016 budget was approved according to the performance evaluation results.
} 
As the extension and expansion of performance objective audit, the ex-ante performance evaluation is mainly to judge whether the Department should pay for the declared project, that is to say, on the one hand, the finance should determine whether the financial support should be provided by the declared project through the aspects of whether the declared project is related to policy, department function, public demand, etc; On the other hand, the ex-ante performance evaluation also needs to judge whether the project implementation plan is effective and whether the measures can guarantee the realization of the expected performance goals. Through the help of the third-party organization, industry experts, project management experts, the former financial department can change the formal audit of performance objectives, which is conducive to further improve the scientific budget decision-making. Beijing has made remarkable achievements since the implementation of the ex-ante performance evaluation in 2010. In 2015, Beijing carried out ex-ante performance evaluation in batches, involving key expenditure items and general expenditure items. In 2018, Beijing put forward a comprehensive way to start the financial performance evaluation in advance by combining the "larger scale performance objective review" and the "key expenditure performance evaluation in advance", ensuring the smooth operation of the chain between performance objective management and performance evaluation in advance. In 2019, Beijing's ex-ante performance evaluation mode will be more innovative, taking two forms of simple procedure and general procedure, greatly improving the evaluation efficiency and expanding the coverage of the ex-ante performance evaluation project. In the past 10 years since the implementation of Beijing's ex-ante performance evaluation, 542 evaluation projects have been completed, with the amount of evaluation fund exceeding 86 billion yuan and the amount of evaluation and reduction nearly 10 billion yuan, saving a lot of money for Beijing's finance.

With the great achievements of Beijing's ex-ante performance evaluation mechanism, many governments have learned to follow suit and saved a lot of budget funds through the ex-ante performance evaluation. For example, in 2019, Jinan City, Shandong Province launched a major policy and project ex-ante performance evaluation, which provided a favorable demonstration for budget decision-making. Eighty-eight projects in multiple industries were ex-ante evaluated, involving a total of 6.62 billion yuan of capital, 2.13 billion yuan of audit reduction, and the audit reduction rate was 32.1\%; ${ }^{3}$ In 2019, Pingshan County, Sichuan Province selected three key projects for evaluation, and the evaluation results of the three projects were "suggested for support","suggested for partial support" and "suggested not for support", which improved the project differentiation.

3 Data source: Jinan carried out ex-ante performance evaluation on 88 projects, reducing 2.13 billion yuan, Shandong News, Liu Yafei, https://sd.dzwww.com/sdnews/201903/t20190318_18512227.htm.

\subsubsection{Performance Management by Objectives in Guangdong}

Guangdong Province began to explore the implementation of budget performance management in 2007, and has been in the forefront of local budget performance management. In 2018, Guangdong Province issued the Performance Index Database of Financial Budget of Guangdong Province and Interim Measures for the Management of Performance Index Database of Financial Budget of Guangdong Province to guide the management of performance index, providing a strong starting point for strengthening the management of budget performance target.

In recent years, the Department of finance of Guangdong Province has adopted the method of "self examination of business department performance + preliminary examination of the third party + reexamination of financial department" to examine the performance objectives listed in the annual budget projects. The business department, the third-party organization and the financial department have two advantages in the way of joint review. First, the third-party professional organization guides the Department's performance budget management, improves the Department's business capacity, and ensures that the performance objectives are completed on time and with quality; Second, after the self-examination and preliminary examination, the Department of Finance selects the key project performance objectives with large amount of funds, long arrangement period and wide influence for reexamination, so as to ensure the audit quality and improve the audit efficiency. At the same time, Guangdong Province has increased internal communication and exchange of the government, fully considered the professional requirements of objective conditions and performance objective management, achieved the integration of performance and budget, and avoided the omission of professional and objective factors in budget decision-making through the establishment of "performance office business office competent department" communication channels, improve the efficiency of inter department information circulation, shorten the budget game time, and ensure the scientific and effective budget decision-making. At present, the performance objective management of Guangdong Province basically covers all types of expenditures of general public budget. In terms of project budget, items that have not declared performance objectives cannot be put into storage, and items that have not passed the audit will not be budgeted in principle.

\section{Problems Existing in Ex-ante Performance Management}

Since 2010, Beijing put forward Ex-ante performance evaluation. In 2015, the Ministry of finance required the central department to implement the performance target management for the use of financial funds. To the State Council of the CPC Central Committee, it required to expand 
the scope of performance appraisal in advance and establish the evaluation mechanism for new major policies and projects in advance. The ex-ante performance management has been implemented in China for nearly 10 years, although some achievements have been achieved, but there are still some problems in practice.

\subsection{The Concept of Performance has Not Been Firmly Established}

Performance objective management is the focus of management in advance, and performance objective setting is the first step of performance objective management, which determines the follow-up management effect. However, in practice, due to the lack of a perfect mechanism of constraint and accountability based on performance objective management in China, the firm performance concept has not been established in the government departments, resulting in many problems in performance objective management in China.

From the perspective of the expenditure department, the ultimate purpose of the expenditure department is to apply for as much money as possible and strive for the greatest discretion. Therefore, he will take all kinds of strategic means to avoid the restriction of performance goal management on the use of his own fund arrangement. At the same time, he will take performance goal as his work and apply for as much financial funds as possible. Therefore, the expenditure department may have the following problems: first, the fund using unit does not pay attention to the performance objective management, or even perfunctory performance objective management, some projects have the same performance objectives, application reasons or content repetition. Secondly, expenditure departments tend to use the general objectives of "effectively promoting regional economic development", "improving public satisfaction", "improving performance management mechanism" to reduce the operability of performance monitoring and performance evaluation, thus affecting the financial sector's supervision effectiveness.

Under the condition that the concept of performance has not been established in China, the accountability mechanism of budget management based on performance has not been firmly combed, the government departments do not have a proper understanding of performance management, lack of motivation to promote reform, and under the premise of lack of strong constraints, the ex-ante performance management is difficult to play its expected role.

\subsection{The Diversification Process of Decision-makers Is Slow}

Theoretically speaking, the successful implementation of ex-ante performance management can effectively improve the scientificity of financial budget decision-making, improve the allocation efficiency of financial funds, and alleviate the increasingly urgent situation of financial funds in China to a certain extent. However, it is very difficult to promote budget performance management solely by the power of the financial department. Therefore, on the one hand, the financial department can improve the quality of budget performance management by introducing third-party organizations and experts in the industry to participate in budget performance management, and improve the recognition and credibility of performance evaluation results from all walks of life; on the other hand, it can be through the network, hearings, etc It is beneficial to build a good relationship between citizens and the government by collecting social conditions and public opinions and making the allocation of funds more in line with the needs of the public.

However, China's third-party market is yet to be improved, and China's "sunshine finance" has not been completed. It is difficult for the general public to directly participate in the specific work of ex-ante performance management. Even if they have published their own opinions and suggestions on government projects through the Internet, hearings, etc., they can only be used as reference materials for budget decision-making rather than the main factors affecting budget decision-making. Therefore, social situation Public opinion plays a very limited role in ex-ante performance management. The lack of participation of social forces in advance performance management will eventually lead to the lack of democracy and scientificity in budget decision-making.

\subsection{Unscientific Setting of Performance Objectives}

When setting the performance target value, in principle, the setting of performance target value should be in line with the principle of "jump, reach", and stimulate the enthusiasm of budget department through appropriate difficulty setting. However, in practice, the expenditure department will set a lower target value based on the principle that it must be able to submit a beautiful report card, so as to ensure that $100 \%$ of the expected performance goals are achieved and pass the performance appraisal. For example, in 2018, the performance target value setting of individual central projects is lower than that of completed projects when they are declared, which seriously restricts the maximum benefit of funds. Fourth, some users use performance objectives as a means to compete for resources, and highlight the importance of the project by linking the project with the country or strategy that is difficult to measure, such as linking the project performance objectives with life, social security, agricultural security, etc., so that the project has incomparable priority, so as to obtain financial arrangements [15]. The expenditure department doesn't pay enough attention to the performance objective management, which leads to the problems such as the inadequate promotion of the performance objective management, the insufficient refinement and quantification of the performance objective, and the unreasonable setting of the performance objective value, etc. the implementation of the performance objective management can't achieve the expected goal, which eventually leads to the serious consequences of the performance objective management to be "performance" or "no effect". 


\subsection{Performance Objectives Are Not Strictly Reviewed}

Under the background of slow growth of fiscal revenue and excessive rigid growth of expenditure in China, ex-ante performance management can help the financial department to make better budget decisions, allocate funds to the most urgent areas, maximize the effectiveness of limited financial resources, and ease the contradiction between fiscal revenue and expenditure. Therefore, compared with other pointed out departments, the financial department has a higher enthusiasm for advance performance management. At present, the financial department still considers enough performance factors in fund allocation, which shows that the audit of performance objectives is not in place.

First, there is no inevitable relationship between performance target setting and fund allocation, and a large number of projects without performance target still receive financial funds [16]. For example, in 2018, there were more than 395 million projects in 8 departments in Guangdong Province, which obtained funding arrangements without declaring their goals.

Second, there is a lack of substantive review of performance objectives. The focus of the review is set to the compliance review of whether the application materials are complete and whether the content is complete, which basically does not involve the scientific review of performance objectives. This "formal" and "walk through" performance objective review mode seriously damages the seriousness of budget performance management in China. For example, in 2018, 17 special transfer payments from the central government, 1 government fund and 273 project performance objectives from 17 departments obtained budget funds when the performance objectives were not clearly set or the elements of relevant management regulations were incomplete. ${ }^{4}$

\subsection{Failed to Effectively Promote the Formation of Project Library}

The scientific and standard rolling project base based on performance objective management has not been formed. In theory, project management is an important starting point of comprehensive budget performance management. Therefore, the most important thing in advance performance management is to promote the formation of a scientific and standardized rolling project library. However, according to the current actual situation, the achievement of advance performance management is not ideal.

In actual work, the opening time of budget preparation is earlier than the annual planning time of administrative institutions, and the units often have no specific work tasks in budget preparation, so there is no project plan or only "fabricated" project plan [17], the lack of project support in fund arrangement makes the prior performance management unable to constrain the budget decision. Furthermore, the lack of effective source support leads to the fact that the project

4Source: Audit Office issues the report on the implementation of the central budget and other financial revenue and expenditure audit in 2018. database cannot achieve dynamic management, and thus cannot meet the requirements of full cycle project management [18].

This may have two consequences. One is that if the project application is not approved, the application department will immediately re prepare the new project to replace the original project. Due to the short preparation time of the new project, there is insufficient argument, which will increase the risk of using financial funds. Another situation is that the funds have been allocated, but the funds are idle because there is no corresponding project. For example, in 2018, due to the lack of a project reserve, the Beijing assistance project did not arrange specific projects for 223 million yuan of assistance funds in eight districts, accounting for $23.05 \%$ of the total investment of the city's assistance funds, reducing the efficiency of fund use. ${ }^{5}$

\subsection{The Coverage of Ex-ante Performance Management Is too Narrow}

Take Beijing as an example. In 2018, Beijing issued policies to expand the coverage of prior performance evaluation to more than 5 million new career development projects (policies) in 2019. In 2019, the total amount of funds to participate in the prior performance evaluation application was 8.049 billion yuan, and the general public budget expenditure of Beijing in that year was 527.13 billion yuan. After the prior performance evaluation, a large amount of funds accounted for less than $2 \%$ of the total, which was conducive to prior performance evaluation Performance evaluation. In other areas of China, the proportion of budget funds in the total amount of project participating in the ex-ante performance management is lower.

At the same time, due to the limited time and energy of the financial department, it often only evaluates the personnel of major projects (policies), which gives the expenditure department room to avoid the evaluation. Take the performance evaluation of over 5 million new business development projects (policies) issued by Beijing in 2018 as an example. In 2018, the total amount of funds for participating in the evaluation project was nearly 40 billion yuan. After the regulations were issued in 2019 , the total amount of funds for participating in the evaluation project was less than 10 billion yuan, and the total amount of funds for participating in the evaluation project was greatly reduced. We can infer that after the promulgation of the new regulations, in order to avoid prior evaluation, the expenditure department may split over 5 million large projects into less than 5 million small projects, so as to avoid prior evaluation.

Most regions only carry out performance evaluation on some major or new projects or policies, and budget units can reduce the probability of being included in the prior performance evaluation by avoiding their own Expenditure Projects becoming "major". However, due to the limited time and energy, the audit requirements of the Ministry of Finance

\footnotetext{
5 source: audit report on Beijing's budget implementation and other financial revenues and expenditures in 2018.
} 
for small projects are lower than those for large projects, which are easier to pass the audit. Therefore, due to the narrow coverage of the ex-ante performance management, a large number of funds wander outside the evaluation in advance, reducing the impact of the ex-ante performance management on the budget decision-making, and improving the efficiency of budget fund distribution is very limited.

\subsection{No Prior Performance Evaluation System has Been Established for the Overall Expenditure of Departments and Governments}

From the perspective of implementation, at present, the project management is the main part of China prior performance management, which is still insufficient for the Department and the government's overall expenditure planning. When the center of ex-ante performance management is the project, there may be a strange phenomenon that the micro level is reasonable and the macro level is unreasonable.

When each project is audited independently, project setting is necessary, but on the whole, the function of this project may overlap with other projects, so there is no need for the project to exist, or there is a conflict between the performance objectives of different projects, that is, the setting of these project performance objectives is actually unreasonable.

Therefore, this kind of project-based management and lack of macro perspective management is not conducive to the overall planning of financial funds, nor can it change or alleviate the "fragmentation" management status of financial funds, which ultimately leads to the difficulty of budget performance management to form a multi-level service for "strategy policy project".

\section{Reform Ideas of Ex-ante Performance Management}

\subsection{Improve Performance Concept and Establish Accountability Mechanism}

The establishment of performance concept is of great benefit to the advance of performance management. At present, the concept of performance management in China has not been firmly established. In addition to the influence of traditional culture, the corresponding accountability mechanism has not been established, the promotion of performance budget management is greatly hindered, and the results of performance management such as evaluation and evaluation are not fully used.

To improve the performance concept and performance budget management ability of expenditure department, first of all, improve the performance awareness of department leaders, change the concept of expenditure, and realize that performance management is not only a tool for the financial department to supervise its own department, but also a sharp tool to improve the efficiency of department management. According to the function of the Department, the development planning, the establishment of projects and the preparation of performance objectives, the budget funds of the Department can effectively provide efficient services for the performance of the functions of the Department and the rapid development of the Department. With the help of experts in the industry and third-party organizations, the performance evaluation in advance can provide opinions for the project design in many aspects, so as to find problems in the project design as early as possible and effectively avoid the implementation of the Department The emergence of various risks in the process.

Secondly, improve the ability of department performance management. Through regular training, gradually improve the ability of department budget performance management, strengthen the integration of performance objectives and strategic objectives, grasp the difficulty of setting reasonable performance objectives, make the setting of project performance objectives quantifiable and measurable, and prepare the budget according to the performance objectives, so as to lay a good foundation for the follow-up performance management.

The financial department must pay attention to the performance evaluation and target evaluation, and allocate funds according to the evaluation and evaluation results, so as to really promote the attention of other departments to performance management. First of all, the financial department should do a good job in checking the professional qualification of the third-party evaluation institutions. If the third-party professional organization is not professional, it may lead to dissatisfaction of the evaluation department due to the unconvinced results, which is not conducive to the promotion of follow-up work. Therefore, the Ministry of finance should not only control the professional qualification of the third-party institutions, but also carry out relevant training for the staff of the third-party institutions, so that the third-party institutions can understand the basic information of the projects to be evaluated and the evaluation needs of the financial department in the shortest time, so as to ensure that the third-party institutions can effectively complete the evaluation and evaluation work in a limited time.

Secondly, the financial department should control the quality of ex-ante performance management. Although the Ministry of Finance entrusts part of the performance management to the third-party organization, the Ministry of finance must do a good job in supervision, not only checking whether the third-party evaluation and review process are compliant, but also conducting spot check on the evaluation and review results, and reevaluating some projects if necessary, so as to ensure the unity and fairness of the evaluation standards and the scientificity and rationality of the evaluation results. The financial department should strictly apply the audit results to the budget arrangement, establish the fund allocation mechanism based on the evaluation and evaluation results, and force the expenditure department to pay attention to the ex-ante performance management.

Finally, the financial department should establish a macro 
perspective of ex-ante performance management. On the one hand, it should push the focus of ex-ante performance management from the project to the policy, and promote the integration of financial budget management with national strategy and development plan, which is conducive to better play the foundation and important pillar role of Finance in national governance. On the other hand, the financial department should check whether there are conflicts in the performance target setting of different departments from the government level, so as to avoid that different functional departments of the government damage each other's interests in order to achieve the performance target and gather government forces to achieve the national strategic target.

\subsection{Promote Full Coverage of Ex-ante Performance Management}

At present, China's ex-ante performance management means mainly include performance objective management and ex-ante performance evaluation. The former has a wider coverage than the latter, and the latter has a deeper and more detailed management than the former, which has a more obvious impact on budget decision-making. Therefore, ex-ante performance management should effectively combine the two, form the integration of ex-ante performance management, and improve the efficiency of ex-ante performance management.

First of all, compared with performance objective management, the workload of ex-ante event performance evaluation is too large to cover all financial funds. Therefore, to expand the coverage of ex-ante event performance management, it is necessary to expand the coverage of performance objective management, include all financial funds into the objective management system, gradually extend the performance objective management to the Department and unit level, even the whole government level, and make actual achievements Effective target management. For the expenditure department, regular training can be carried out to improve the performance awareness and performance management ability. A third party can be employed to guide the setting of performance objectives of the expenditure department, and gradually improve the quality of setting performance objectives. At the same time, the financial department must pay attention to the audit of performance objectives, and establish a mechanism to effectively link the audit results and budget allocation, so that the performance objective management can really play a role.

Secondly, we should expand the coverage of performance evaluation in advance by means of "simplicity + emphasis". Compared with performance objective management, ex-ante performance evaluation is more strict in project audit and better in risk control of project follow-up. Although the effect of ex-ante performance evaluation is better than performance objective management, its workload is also larger. The financial department has limited financial resources, energy, human resources and so on, which leads to a small number of ex-ante event performance evaluation projects. Therefore, we can adopt the combination of simple evaluation and key evaluation, and add a new evaluation method between the current key ex-ante event evaluation and performance objective review. On the one hand, it can expand the coverage of ex-ante event performance evaluation, on the other hand, it can expand the coverage of ex-ante event performance evaluation It can alleviate the evasive behavior of the expenditure department to a certain extent.

Finally, we should pay attention to the organic connection of the two kinds of management methods in advance. At present, China's prior performance management focuses on major projects or policies. For non-major projects, performance objective auditing is basically adopted. However, the total amount of these non-major projects accounts for a large proportion of the total financial expenditure. If we can't manage these non-major projects well, it's impossible to improve the performance of financial funds. Therefore, the projects participating in the ex-ante performance evaluation cannot be selected on the amount or impact, but should consider the completion of the performance objectives of the previous year. If the performance evaluation results of a department in the previous year are not good, then this year should focus on the performance evaluation of the Department's projects, so that professional forces outside the Department can help the department do a good job in the project planning of this year. On the one hand, the effective integration of performance objective management and prior performance evaluation is conducive to improving the impact of performance objective management on budget decision-making.

\subsection{Establish Multiple Channels for Public Participation in Ex-ante Performance Management}

Open and transparent budget is the essential requirement of public finance and the basic feature of democratic budget. Good budget performance management is not only need to be recognized by citizens, but also need citizens to participate in the whole process of budget preparation, approval, implementation, adjustment and review. From the perspective of the subject of budget participation, citizen participation in budget can be divided into two forms: individual participation and social organization participation. ex-ante performance management should not only deepen the breadth and depth of third-party participation, but also establish an effective channel for individual citizens to participate in ex-ante performance management.

To deepen the third party's participation in the ex-ante performance management, we can start from the following aspects: first of all, to improve the laws and regulations of the third party's participation in the performance management is conducive to regulating the third party market, ensuring the professionalism of the third party organization, so as to increase the credibility of the third party's evaluation and evaluation results, and to clear the obstacles for the third party's further participation in the performance management. Secondly, appropriately extend the working hours of the third party to ensure the quality of work. With the implementation of comprehensive budget performance management, the 
workload of ex-ante performance management has also increased. It is difficult to do more detailed audit on the project based on the original work, which may result in half the effort. Therefore, it is necessary to appropriately extend the time of third-party evaluation and review of the project, and allow enough time to carry out field visits, hold symposiums, etc., so as to ensure the authenticity and reliability of the evaluation results.

To establish an effective channel for citizens to participate in the ex-ante performance management, firstly, the expenditure department shall carry out hearings and consultation meetings for major livelihood projects, take relevant public opinions seriously, and plan projects according to the needs of the public; secondly, for the review of departmental livelihood projects, the financial department can select representatives from the relevant population of the project, so that the representatives can participate in the ex-ante performance management, From the perspective of demanders, provide opinions for project review and evaluation; finally, to improve budget transparency, we should not only expand the coverage of budget performance information disclosure, improve the level of information disclosure and detail, and increase the stability of public information, but also improve citizens' budget literacy, so that the public can truly understand the budget, and participate in budget management through budget supervision.

\section{Conclusion}

Ex-ante Performance Management has been implemented for many years in China. It is based on performance objectives and ex-ante evaluation to achieve effective management of project budget. However, there are still many problems in the performance management in advance, such as the performance concept is not deep enough, the performance goal setting is not scientific, the performance goal evaluation is not strict, the coverage of the ex-ante evaluation is too narrow, and the application of the evaluation results is not sufficient, which may hinder the full implementation process of China's budget performance management. To solve these problems, first of all, we should improve the performance awareness, clarify the responsibility constraints of performance management and strengthen the incentive constraints of performance management, so as to force the expenditure departments to pay attention to the performance of the use of financial funds; second, we should further expand the coverage of performance management in advance, not only covering the four budgets, but also reflecting the performance of the use of financial funds and the effect of policy implementation in a comprehensive and multi-dimensional way. After that, we should establish various channels for the public to participate in the performance management in advance, improve the scientificity and democracy of budget decision-making through the combination of internal management and external supervision, and ensure the high allocation efficiency and use efficiency of financial resources.

\section{References}

[1] Wang Haitao. Research on the reform of budget performance management in China [D]. Institute of financial science, Ministry of finance, 2014.

[2] Chen Kai, Xiao Peng. International comparison and Enlightenment of budget performance target management -Based on the research perspective of target setting theory [J]. Economic research reference, 2019 (12): 68-78.

[3] Cao Zheng. Analysis on the management of departmental budget performance objectives [J]. Accounting learning, 2019 (15): $165+167$.

[4] Zheng Fengzi. Problems and suggestions on performance target management of department budget -- Based on performance target data of Financial Expenditure Projects of Shanghai municipal budget department $[\mathrm{J}]$. Financial supervision, 2019 (02): 42-45.

[5] Jiang Shujun, Liang Lijuan. Some thoughts on the full implementation of performance target management [J]. Financial supervision, 2019 (05): 49-52.

[6] Tong Wei, Ying Xiaoyu. Methods to improve performance target management [J]. New financial management (government financial management), 2018 (11): 52-54.

[7] Tong Wei, Tian Yaqiong. Performance evaluation of department overall expenditure in advance: method and implementation path [J]. Reference for economic research, 2017 (51): 3-11.

[8] He Qing, Zhang Bin. Performance evaluation of China's fiscal expenditure: institutional framework and local practice $[\mathrm{J}]$. Journal of theory, No. 10, 2012.

[9] Zhu Jing. Difficulties and solutions: a number of experts talk about performance evaluation in advance $[\mathrm{J}]$. New financial management (government financial management), 2015 (01): 76.

[10] Jiang Zhu, Chen Jia. Performance evaluation of department overall expenditure in advance [J]. New Finance (Government Finance), 2017 (04): 77-79.

[11] Nie Fengiie. Research on the decision-making mechanism of China's public budget [D]. China Academy of financial Sciences, 2014.

[12] Ma caichen, Yuan Jiao. Dynamic equilibrium analysis of timeliness of public budget decision [J]. Economic and management research, 2017, 38 (06): 84-95.

[13] Wang Yongjun. Reform from public budget procedure to government decision-making system [J]. New financial management (government financial management), 2016 (07): 26-27.

[14] Wang Zecai. Budget performance management: the way to fully implement performance management in the new era $[\mathrm{J}]$. China Administration, 2018 (04): 6-12.

[15] Gou Yannan Avoiding competition: a study of strategic behavior in public budget expenditure decision [J]. Journal of Guizhou University (SOCIAL SCIENCE EDITION), 2007 (04): 23-27.

[16] Jiang Haiyong, Yang Qingyuan. Discussion on the management of departmental budget performance target [J]. Law and economy, 2015 (19): 28-30. 
[17] Zhao Liang. Practice and thinking of improving the budget management level of administrative institutions with the construction of project library as the starting point) For example, the construction of the project database of the municipal budget department [J]. Economist, 2018 (04): 98-99 +101 .
[18] Zheng Zhijie. Thoughts and suggestions on building a budget management model supported by project database, asset database and basic information database [J]. Budget management and accounting, 2019 (07): 17-20. 